\title{
The LCMV gp33-specific memory T cell repertoire narrows with age
}

\author{
Adam Bunztman ${ }^{1}$, Benjamin G Vincent ${ }^{2,3}$, Harsha Krovi ${ }^{1}$, Shaun Steele ${ }^{3}$ and Jeffrey A Frelinger ${ }^{1 *}$
}

\begin{abstract}
Background: The memory response to LCMV in mice persists for months to years with only a small decrease in the number of epitope specific CD8 T cells. This long persistence is associated with resistance to lethal LCMV disease. In contrast to studies focused on the number and surface phenotype of the memory cells, relatively little attention has been paid to the diversity of TCR usage in these cells. $C D 8^{+} T$ cell responses with only a few clones of identical specificity are believed to be relatively ineffective, presumably due to the relative ease of virus escape. Thus, a broad polyclonal response is associated with an effective anti-viral $C D 8^{+} T$ cell response.

Results: In this paper we show that the primary $C D 8^{+} T$ cell response to the LCMV gp33-41 epitope is extremely diverse. Over time while the response remains robust in terms of the number of gp33-tetramer ${ }^{+} \mathrm{T}$ cells, the diversity of the response becomes less so. Strikingly, by 26 months after infection the response is dominated by a small number TCR $\beta$ sequences. In addition, it is of note the gp33 specific CD8 ${ }^{+} \mathrm{T}$ cells sorted by high and low tetramer binding populations 15 and 22 months after infection. High and low tetramer binding cells had equivalent diversity and were dominated by a small number of clones regardless of the time tested. A similar restricted distribution was seen in NP396 specific CD8 ${ }^{+} T$ cells 26 months after infection. The identical TCRV $\beta$ sequences were found in both the tetramer ${ }^{\text {hi }}$ and tetramer ${ }^{\text {lo }}$ binding populations. Finally, we saw no evidence of public clones in the gp33-specific response. No CDR3 sequences were found in more than one mouse.

Conclusions: These data show that following LCMV infection the CD8 ${ }^{+}$gp33-specific CD8 T cell response becomes highly restricted with enormous narrowing of the diversity. This narrowing of the repertoire could contribute to the progressively ineffective immune response seen in aging.
\end{abstract}

Keywords: CD8 T cell, T cell repertoire, T cell receptor, Aging

\section{Background}

The cell mediated immune response is critical in the clearance of many viral infections. Lymphocytic choriomeningitis virus (LCMV) is one the most widely studied acute viral diseases in experimental animals [1,2]. For LCMV clearance there are critical roles for both $\mathrm{CD} 4^{+}$ and $\mathrm{CD}^{+} \mathrm{T}$ cells, but it is clear that $\mathrm{CD}^{+}$memory cells are vitally important for the resistance to secondary challenge $[3,4]$. In LCMV infections there are three distinct phases of the CD8 T cell responses: priming, expansion and contraction [4]. Following virus clearance, antigen specific $\mathrm{CD}^{+} \mathrm{T}$ cells persist as memory cells for many months- essentially the lifetime of the mouse [5]

\footnotetext{
* Correspondence: jfrelin@email.arizona.edu

${ }^{1}$ Department of Immunobiology, University of Arizona, Tucson, AZ 85724, USA

Full list of author information is available at the end of the article
}

and the persistence of $\mathrm{T}$ cells may or may not depend of signaling through TCR depending on the specificity of the $\mathrm{T}$ cell [6]. Intensive work has shown that the number of antigen specific $\mathrm{CD}^{+} \mathrm{T}$ cells in mice declined only slowly over time. In mice the half life for tetramer ${ }^{+} \mathrm{CD} 8^{+}$ $\mathrm{T}$ cells in the spleen was nearly 2 years [7]. This long lifespan has been seen in many virus specific $\mathrm{T}$ cell populations in both mouse and man [8-10].

In contrast, the body of work enumerating the number of LCMV specific CD8 T cells, the T cell receptor diversity of those cells has been investigated only sporadically. Lin and Welsh examined the total TRVß13-3 (IMGT nomenclature is used throughout, older nomenclature is translated to IMGT) repertoire by spectrotyping [11]. They concluded that the repertoire changed little after virus clearance, although superinfection with an unrelated virus did change the LCMV specific repertoire

\section{Biomed Central}


significantly [12]. Similarly, Blattman et al. found little change between the primary and secondary responses in terms of TCR repertoire, but their characterization was also limited to spectratyping [13]. Others have found a similar large diversity of LCMV specific clones following tetramer sorting after acute LCMV infection [14].

In aging, humans and mice often display an accumulation of a single $\mathrm{T}$ cell clone that might occupy as much as $30 \%$ of the total $\mathrm{CD}^{+} \mathrm{T}$ cells [15-18]. This is known as $\mathrm{T}$ cell clonal expansion (TCE). $\mathrm{T}$ cell expansions have a memory phenotype and are widely believed to arise from existing memory cells. These TCE are apparently inherently unstable and have a variable phenotype [19-23]. While there has been significant interest in these cells and their function, there has been relatively little work performed to link the TCE to virus specific T cells.

Relatively little work exists concerning the overall TCR $\beta$ diversity of the virus specific responses measured directly ex vivo. Much of the data involves the use of either $\mathrm{T}$ cell cloning or spectratyping to evaluate the overall repertoire. In the case of spectrotyping, these results can both under and over-estimate the diversity. T cell cloning is plagued by strong selection for cells able to grow in vitro. Much of the literature on TCE suggests that these cells grow poorly in vitro and so would be under counted in experiments that require growing $\mathrm{T}$ cells.

In this study we have examined the repertoires of CD8 T cells specific for the LCMV epitope gp33 immediately following infection and more than two years later, The epitope specific $\mathrm{T}$ cells slowly declined in numbers as expected. The initial response was highly diverse with an essentially a flat distribution and no clone representing more than $3 \%$ of the total epitope specific $\mathrm{CD}^{+} \mathrm{T}$ cells. While the fraction of epitope specific cells was nearly constant, the diversity was dramatically restricted with age. When the mice were tested at 15 months following infection we found that the diversity had decreased with $17 \%$ of the $\mathrm{gp}^{2} 3^{+}$response represented by a single $\mathrm{V} \beta$; by 26 months $100 \%$ of the gp33-specific TCR $\beta$ sequences were a single TCR $\beta$ clone in one of the mice. Only 13 unique sequences were found in the other 26 month old mouse. This strongly supports the idea that clonal expansions do not arise from a distinct lineage, but from the regular memory pool as has been previously proposed $[16,24]$.

\section{Results}

We report a total $1143 \mathrm{~V} \beta$ sequences from individual $\mathrm{CD}^{+} \mathrm{T}$ cells isolated from five mice at varying times before and after LCMV infection. We evaluated a single mouse at 23 days, 15 and 22 months after infection. Two mice were tested 26 months after infection. We recovered 375 unique TCR $\beta$ sequences specific for gp33 specific $\mathrm{CD}^{+} \mathrm{T}$ cells. We have deposited all sequences in GenBank (Accession numbers JX277204 - JX277543) and summarized the results in Additional file 1: Table S1.

\section{$\mathrm{V} \beta$ Usage}

We report here 55 randomly sequenced TCR $\beta$ sequences. In addition we have sequenced 120,000 TCR V $\beta$ from unselected B6 splenic T cells (Buntzman, Krovi and Frelinger, unpublished). These sequences have a similar distribution of $\mathrm{V} \beta$ usage consistent with previous work by others (reviewed in [25]). The $\mathrm{V} \beta$ usage in the 55 single cells is reported here and is shown in Figure 1. When we sequenced TCR $\beta$ from gp33 sorted $\mathrm{CD}^{+} \mathrm{T}$ cells 23 days following infection with LCMV, we found 132 different sequences (Additional file 1: Table S1). Eight per cent were TRV $\beta 13-3$ (Figure 1). However we also found $10 \%$ TRV $\beta 12-2$ and nearly equivalent numbers of TRV $\beta 3$, TRV $\beta 12-1$ TRV $\beta 16$ and TRV $\beta 30$. We compared the pattern of $\mathrm{V} \beta$ usage between the naïve and 23 day post infection $\mathrm{V}$ gene usage and found a significant correlation $(\mathrm{p}<.003)$ demonstrating that the initial gp33 specific repertoire is large and representative of the overall diversity.

\section{Entropy Decline}

Entropy has been used by ecologists to describe the combined species richness (the number of species present) and the distribution of species present (the percentages of the total individuals of each species) $[26,27]$. This number is analogous to chemical entropy as it measure the total disorder in a system. Thus a population with more species has a higher entropy, as does one with a flatter distribution of the number of individuals of each species. We have chosen to use the Shannon entropy as the index of diversity that accounts for both the number and distribution of species as previously described by our group (41). The entropy is calculated from the sequence data- that is the number and distribution of VI and CDR3. When we compared the entropy between the day 23 and naïve $\mathrm{T}$ cells, both had similar, large entropy (6.4 compared to 6.5) (Figure 2), consistent with high species richness and the lack of dominant clones. Based on the spectratyping analysis of B6 mice we had expected the number of T cell receptor CDR3 to be relatively restricted [13]. Instead we found TRV $\beta 13$ genes were used as predicted although they represented only a small fraction $(8 \%)$ of the gp33 response. This indicates that spectratyping can significantly underestimate the diversity of the $\mathrm{T}$ cell receptors used. We emphasize that these sequences came from tetramer sorted single cells.

We sequenced TCR from $g \mathrm{p} 33^{+} \mathrm{T}$ cells from the spleens of mice 15 months after infection. By this time, the response had significantly fewer unique TCR $\beta$ 


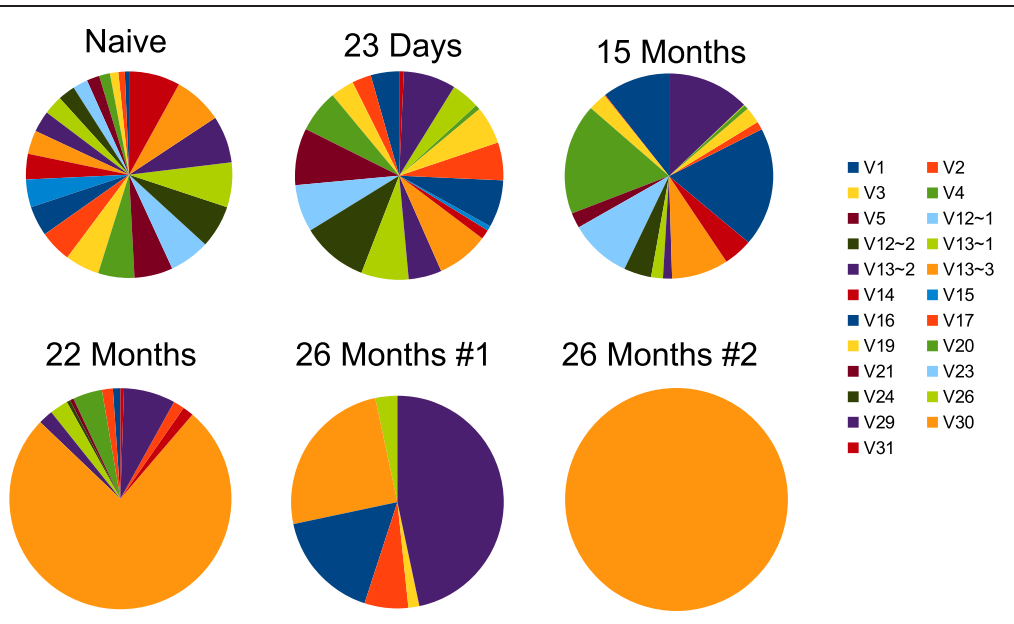

Figure 1 Pinwheel depiction of the TCRV $\beta$ usage of gp33-tetramer ${ }^{+}$cells following infection with LCMV. Naive represents the unimmunized repertoire. Each pinwheel represents the distribution of TCRV $\beta$ from tetramer sorted cells from a single mouse. Two mice were tested at 26 months, designated \#1 and \#2. The number of cells sequenced in each pinwheel is: naïve, 55; 23 Days, 136; 15 months, 705; 22 months, 187; months 26 mouse 1, 60; 26 months mouse 2, 64. The entire CDR3 sequences have been deposited in Genbank, Accession numbers: [Genbank:JX277204 - JX277543].

represented (Figure 1), We found only 141 different clones among the 705 TCR sequenced. Further, there was a narrowing of the V $\beta$ usage, with TRV $\beta 16$ present in the highest frequency $(18.7 \%$ followed by TRV $\beta 4$, 17.4\%; TRV $\beta 1,10.5 \%$; TRV $\beta 12,9.6 \%$ and TRV $\beta 13-3$, $12.7 \%$ ). Together, these make up $67 \%$ of the sequences recovered. At 15 months post infection the entropy had decreased from 6.5 to 3.8 , a large decrease in diversity (Figure 2). There was no significant correlation of TRV $\beta$ usage with the 23 day post infection repertoire, consistent with the narrowing of the responsive repertoire as measured by the large decrease in entropy. There was also no significant correlation with the naïve repertoire $\mathrm{V} \beta$ usage.

We performed an identical experiment sorting gp $33^{+} \mathrm{T}$ cells at 22 months post infection. Here we recovered $187 \mathrm{~V} \beta$ sequences. In this mouse $75 \%$ of the $\mathrm{V} \beta$ sequences were TRV $\beta 13-3$, with $8 \%$ TRV $\beta 29$. Of the 142 TRV $\beta 13-3$ sequences recovered, there were only two unique sequences represented. This was a marked change from the 15 month sample. As would be expected from the clonal dominance, the entropy had further decreased to 1.8 . There was a

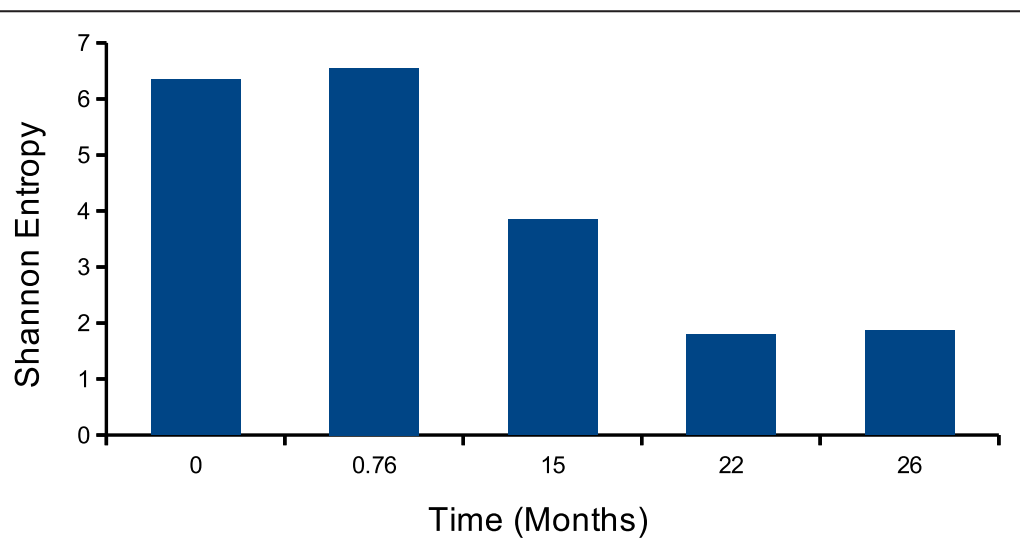

Figure 2 Shannon Entropy of the TCRV $\beta$ usage of gp33 tetramer ${ }^{+}$CD8 T cells over time following infection with LCMV. Shannon entropy was calculated for each distribution using the pooled data from tetramer high and low cells at 15 and 22 months. The entropy was calculated separately for the 26 month mice and averaged. 
significant correlation with the $\mathrm{V} \beta$ usage with the 15 month sample as judged by Pearson's correlation $(\mathrm{p}<.001)$.

In the sample from two mice 26 months after infection, the $\mathrm{V} \beta$ usage had decreased even further. One of the mice used only a single $V \beta$ and CDR3. The other mouse used only $6 \mathrm{~V} \beta$ with TRV $\beta 29$, TRV $\beta 13-3$ and TRV $\beta 16$ making up the majority of the cells (Figure 1 ). Using only the data from the more diverse mouse, the entropy had decreased still further (Figure 2).

We performed an identical analysis on $J \beta$ usage (Figure 3). Using the same approaches we found the same results- $J \beta$ usage decreased as a function of time after infection and the same conclusion is reachedthere is a sequential enrichment of a relatively small number of clones.

\section{$\mathrm{V} \beta \mathrm{J} \beta$ pair usage narrows over time}

Using the specific combination of $\mathrm{V} \beta \mathrm{J} \beta$ pairs, Figure 4 shows the striking narrowing of the repertoire. We show the pinwheel of the initial $\mathrm{V} \beta \mathrm{J} \beta$ pairs after initial infection, but by 15 months the pattern had strikingly simplified. At 26 months post infection just four $\mathrm{V} \beta \mathrm{J} \beta$ combinations represented $82 \%$ of the clones, TRV $\beta 2-/ J \beta$ 2-1, 25\%; TRV $\beta 29 / \mathrm{J} \beta$ 2-5, 22\%; TRV $\beta 13-3 / \mathrm{J} \beta$ 1-1, 20\% and TRV $\beta 16 / \mathrm{J} \beta 2-515 \%$. In a second 26 month post infection mouse $100 \%$ of the gp33-specific $\mathrm{T}$ cells were TRV $\beta 13-3 / J \beta$ 2-7. Thus, the dominance of the TRV $\beta 13-$ $3 \mathrm{~T}$ cells varies from mouse to mouse, but the narrowing of the repertoire did not.

Strikingly, no TCR CDR3 were shared among any of the these mice. Here we found no evidence of public phenotypes in the gp33-specific $\mathrm{D}^{\mathrm{b}}$ restricted response.

\section{Slow decline in gp33 specific T cells}

The number of gp $33^{+} \mathrm{CD}^{+} \mathrm{T}$ cells decreased slowly over time as has been previously reported [28]. However, the decrease was relatively small in our experiment; decreasing from $3 \%$ of $\mathrm{CD}^{+}$(measured in a separate experiment) to approximately $1.7 \%$ over the two year period of observation (Figure 5). Thus there is a two fold decrease over this time period. The loss of heterogeneity cannot be accounted for simply by the selective loss of $\mathrm{gp} 33^{+} \mathrm{CD}^{+} \mathrm{T}$ cells since the frequency of gp $33^{+} \mathrm{T}$ cells remains high. This is similar to the frequency of loss of virus specific $\mathrm{T}$ cells previously reported [5,7-10].

\section{$V \beta$ sequences are shared in high and low tetramer binding $\mathrm{CD}^{+} \mathrm{T}$ cells}

We sorted gp $33^{+} \mathrm{T}$ cells from the 15 month post infection spleens into high and low tetramer binding populations. We compared the TCR $\beta$ sequences from gp $33^{\text {hi }}$ tetramer binders with the gp $33^{\text {lo }}$ binders. The amount of tetramer bound is often used to estimate the affinity of the TCR in cells, with higher binding thought to represent high affinity $\mathrm{T}$ cells. When we analyzed those populations separately we found a very similar distribution of $\mathrm{V} \beta$ usage as well as a number of identical sequences in both the 15 month tetramer ${ }^{\text {hi }}$ and tetramer ${ }^{\text {lo }}$ samples (Figure 6). Twenty-nine V $\beta$ sequences were shared between the two populations. Since each sequence is derived from a single cell, the duplication of sequences cannot be attributed to sequencing artifacts. Indeed, one sequence appears 42 and 75 times in the high and low binding populations respectively.

We performed a similar experiment with a 22 month post infection mouse. We sorted gp $33^{+} \mathrm{CD}^{+} \mathrm{T}$ cells
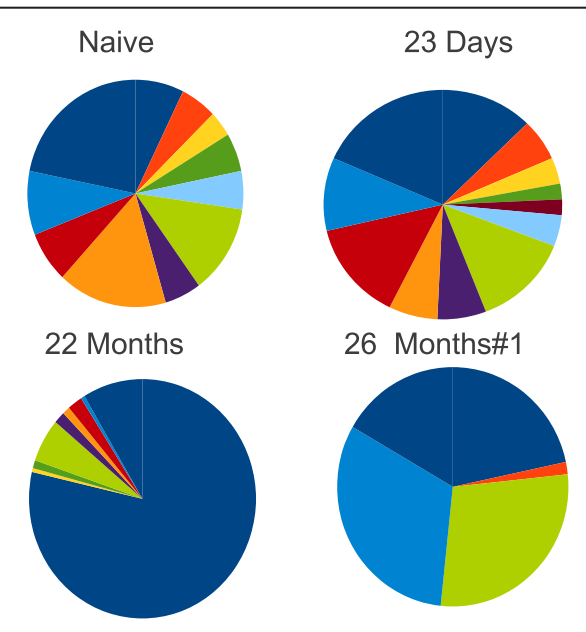

15 Months

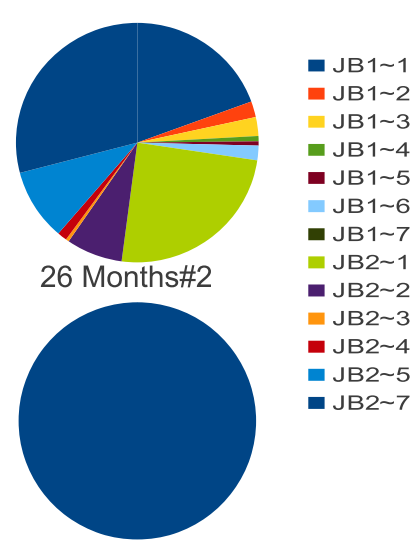

Figure 3 Pinwheel depiction of the TCR J $\beta$ usage of gp33-tetramer ${ }^{+}$cells following infection with LCMV. Naive represents the unimmunized repertoire. The distributions are derived from the same sequences described in Figure 1. 

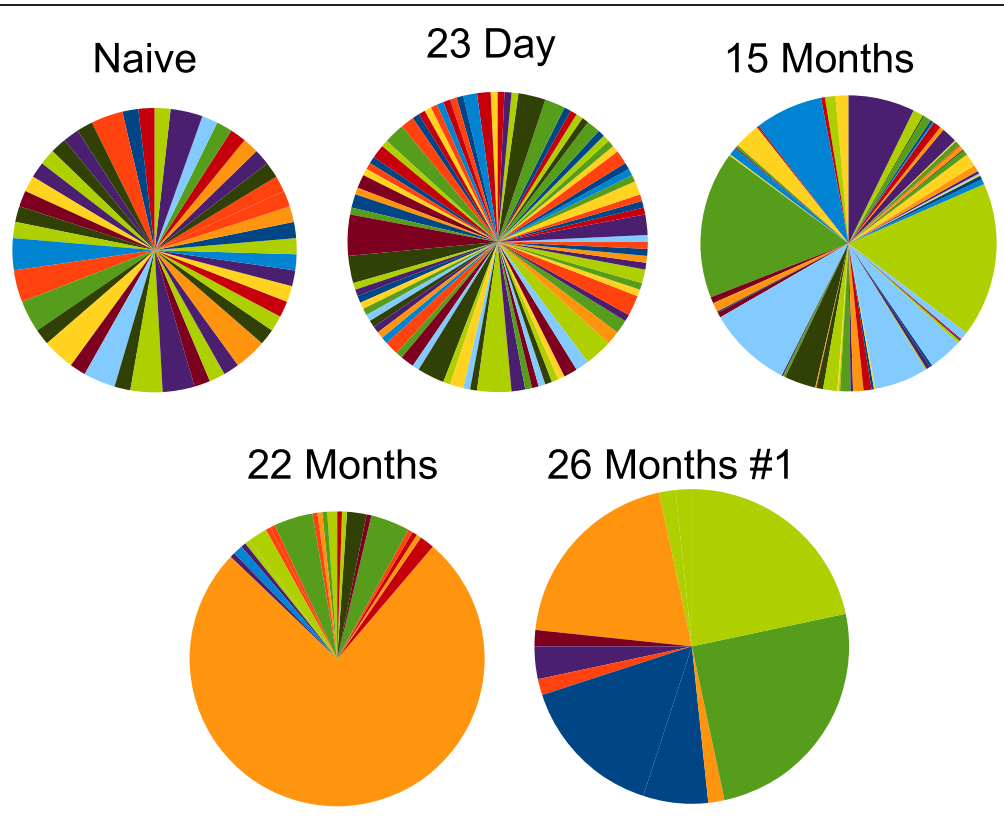

Figure 4 Pinwheel depiction of the $V \beta J \beta$ pairs used in gp33-tetramer ${ }^{+}$cells following infection with LCMV. Naive represents the unimmunized repertoire. The distributions are derived from the same sequences described in Figure 1. The legend is not shown because it is impossible to display all 284 VJ combinations.

into high and low binding populations and found that there was little difference between the high and low tetramer binding cells. Both were dominated by the same TRV $\beta 13-3$ sequence and both used J $\beta$ 1-1 with one sequence present 61 and 81 times in the tetramer high and low populations respectively (Figure 6). When we examined the $J \beta$ usage in tetramer ${ }^{\text {hi }}$ and tetramer ${ }^{\text {lo }}$ binding cells we found the same result (Figure 7) with there

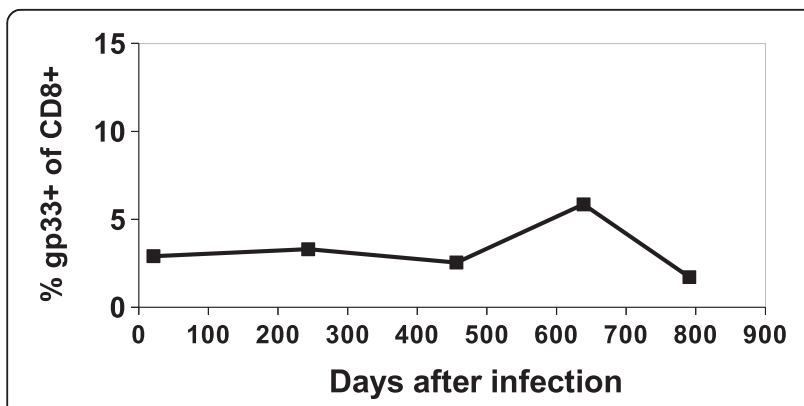

Figure 5 Stability of the fraction of gp 33 tetramer $^{+} \mathrm{T}$ cells over time following LCMV infection. Here we show the fraction of CD8 ${ }^{+}$ cells that were stained with the LCMV-D ${ }^{b}$-gp33 tetramer at each time. Data shown is from the primary sort files, except for the 23 days sames which comes from a separate experiment and is an average of 3 mice. Pearson correlation coefficient shows no significant correlation with time.

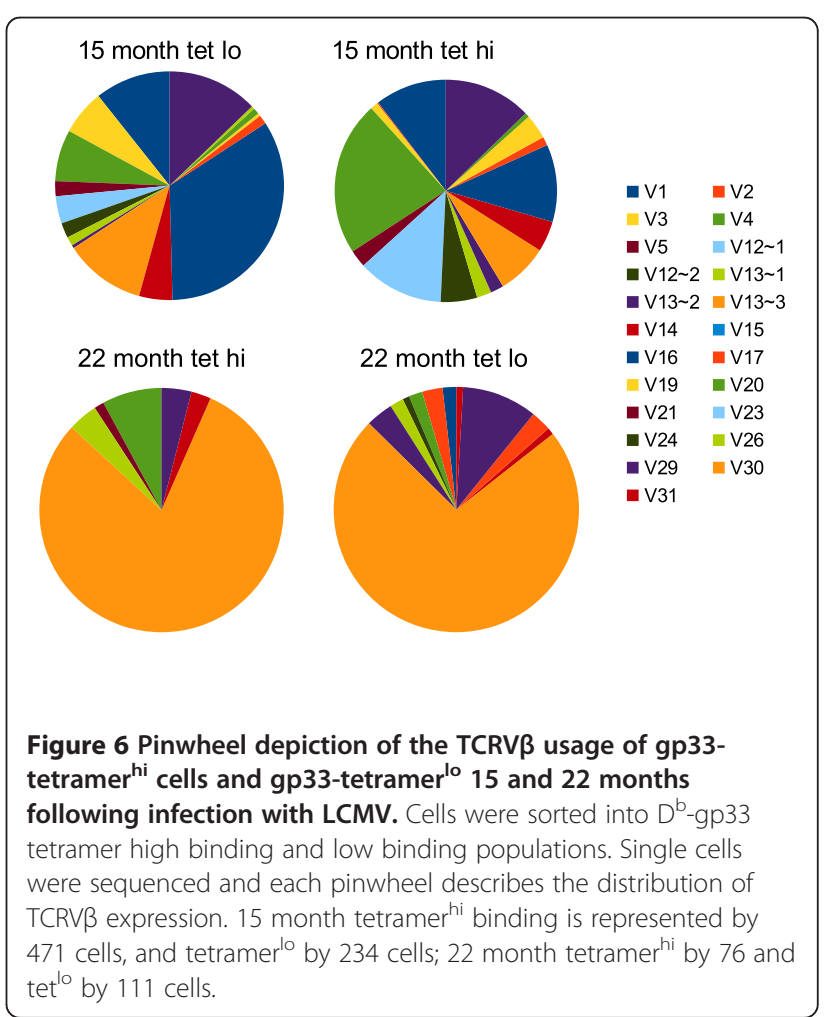




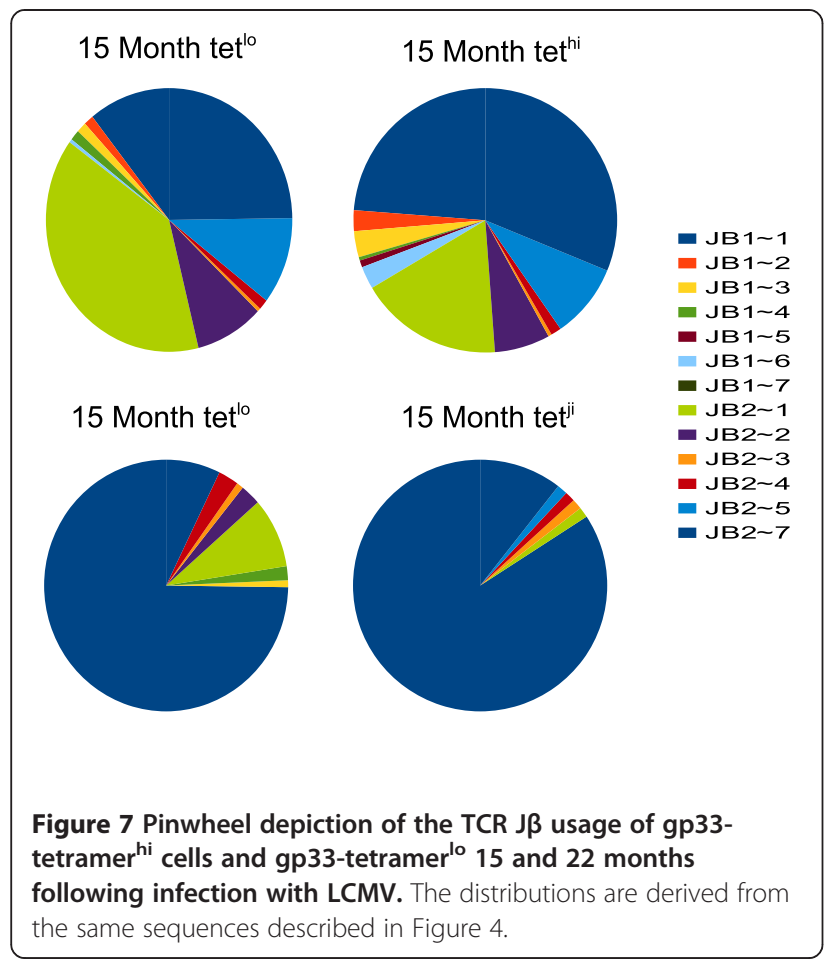

being no significant difference in $J \beta$ usage in tetramer ${ }^{\text {hi }}$ and tetramer ${ }^{\text {lo }}$ cells. While it is possible that the shared sequences express different $\mathrm{V} \alpha$ chains it seems unlikely that all of the differences in tetramer binding would be due to differences in affinity mediated by $V \alpha$.

\section{NP396 specific $\mathrm{CD}^{+} \mathrm{T}$ cells also have a restricted repertoire in old mice}

To determine if this phenomenon was limited to gp33 specific T cells we sequenced NP396 specific T CD8 ${ }^{+} \mathrm{T}$ cells at 26 months in the same mice that were donors for the gp33-specific T cells. Figure 8 shows the usage of TRV $\beta, J \beta$ and $V \beta / J \beta$ pairs in these mice. As we saw with the gp33 specific T cells, the NP396 specific T cells also had a restricted repertoire compared to the naïve cells (Figure 1 compared to Figure 8). These NP396 tetramer ${ }^{+}$ $\mathrm{T}$ cells represented $2.5 \%$ and $0.6 \%$ of the $\mathrm{CD}^{+} \mathrm{T}$ cells from 2 mice, so their frequency was similar to that of the gp33 specific T cells. The calculated entropies of 3.4 and 2.5 , is very similar to those found in the gp33 tetramer $^{+} \mathrm{CD}^{+} \mathrm{T}$ cells. Thus, although we do not have data from earlier time points for the NP396 specific T cells, in old mice the memory repertoire was similarly contracted to the gp33 specific repertoire.

Together these data require that some TCR $\beta$ increase at the expense of the other LCMV specific T cells recognizing the same epitope. This is not a simple survival advantage, but must include a proliferative advantage because the loss of the other clonotypes is not sufficient

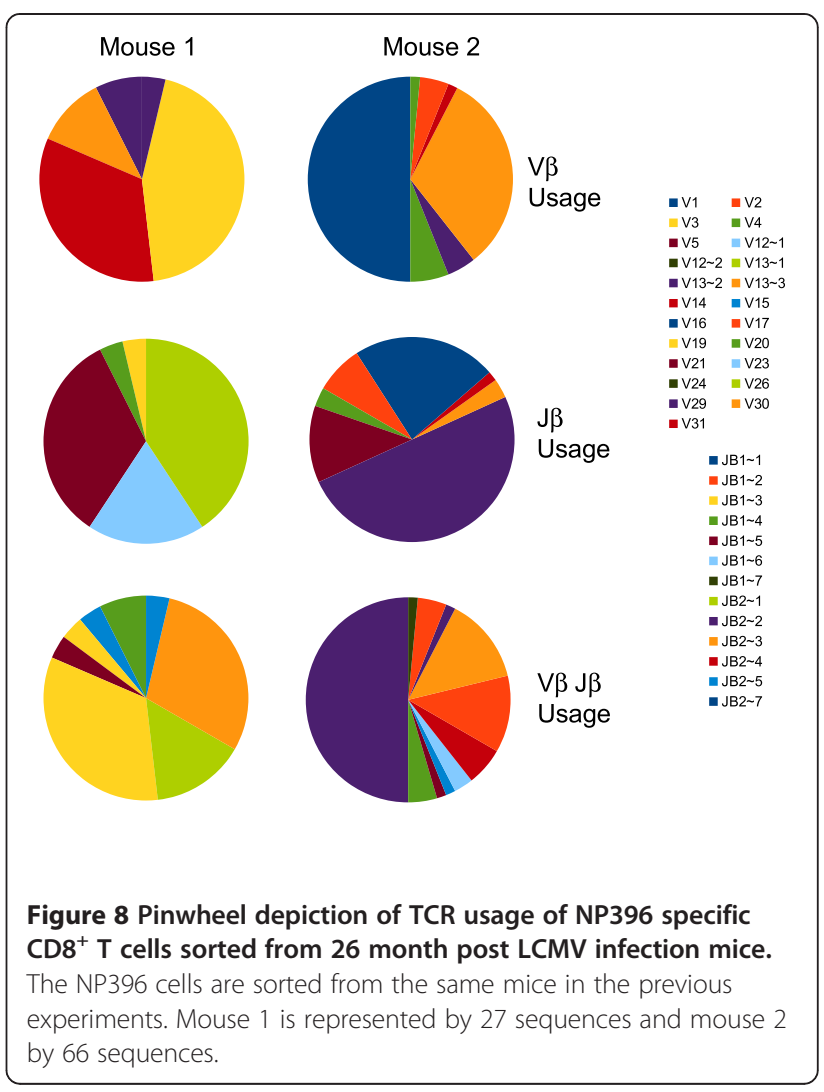

to account for the increase in the dominant clones. The data presented here not speak to any mechanism for the decreased variability, but could result from fortuitous expression higher expression of receptors for IL-5 or IL-15 that are completely unrelated to the T cell receptor. Further, although TRV $\beta 13-3$ was always an important component of the response, its dominance varied from $100 \%$ down to $20 \%$.

\section{Discussion}

As mammals age, they become increasingly unable to mount de novo immune responses [21,29,30]. Surprisingly, even pre-existing immune responses may also be impaired [31]. There are three broad, nonexclusive explanations for this. First, antigen specific cells might be absent; second, the antigen specific clones might be present, but unable to respond, and finally, the specificity of the clones might be off target as in the case of dengue fever [32]. The data we and others have found in old mice suggests that at least a substantial frequency of $\mathrm{CD}^{+}$memory $\mathrm{T}$ cells are present that are able to bind $\mathrm{MHC} /$ peptide complexes in the form of tetramers [29]. Therefore it seems unlikely that the first explanation is correct. However, the fact that many of the clones express a common TCR $\beta$ chain hints that the clones might have a restricted specificity, rather than being anergized. 
The initial response to gp33 is very diverse. As a result, the $V \beta$ usage is significantly correlated with the naïve repertoire. The correlation of the LCVM specific repertoire with the naive repertoire is not surprising considering its high entropy. $\mathrm{V} \beta$ usage in the 15 month repertoire is not significantly correlated with the naive repertoire, although there is a significant correlation with the day 23 sequences. This is consistent with the continuous narrowing of the response, where each new repertoire measurement would be a subset of the previous one but with most of the clones disappearing over time. The observed restriction was most pronounced in the 26 month post infection samples where in one mouse we observed 4 dominant V $\beta$ sequences, and in another we saw a single $\mathrm{V} \beta$ sequence. To establish this definitively, sequential sequence analysis of the repertoire within a single mouse would need to be followed over time.

We also analyzed the V $\beta J \beta$ pairs. This analysis is substantially less robust due to the large number of pairs (284) of $\mathrm{V} \beta \mathrm{J} \beta$ combinations. In this analysis we found no clear pattern as we did in the $\mathrm{V} \beta$ usage and showed no significant correlations by Pearson's test.

There are many reports concerning TCE in both mice and humans $[15-20,22,23,33,34]$. There is no clear consensus concerning the genesis of TCE except the expansions are not malignant cells and are not associated with any obvious pathology. Substantial speculation exists as to the source of the expanded $\mathrm{T}$ cells. The data we present here is completely consistent with TCE being derived from the normal $\mathrm{T}$ memory pool. In the two old mice we examined, it is possible that both would be detected as TCE, although the expansion in mouse 1 might be below the level of detection. For mouse 2 the frequency of gp33-specific T cells was still over 3\% and there was essentially only a single gp33 clonotype detected. Even in bulk sequencing of TCR $\beta$ from this mouse an expanded clonotype of this size would be easily detected as an expansion of the TRV $\beta 13-1$ family. We speculate that TCE are the result of a predictable narrowing of the repertoire of a highly immunogenic challenge to the immune system.

It is tempting to speculate about the biological impact of such a narrow gp33 response. We know that infection of a monoclonal gp33 P14 mouse with high titer virus stock results in the selection of escape mutants [35,36]. We might predict that a similar event would happen if these mice were rechallanged with LCMV. However, other anti-LCMV [37] specific T cells are present. Memory responses to NP396 are well documented following LCMV infection. We observed a high frequency of NP396 specific cells even after 26 months. Thus in vivo, while there might be escape mutants favored for a specific epitope for effective virus persistence, the virus would need to nearly simultaneously mutate multiple epitopes at once, which seems unlikely.

The mechanism by which such expansion of CD8 T cells would arise is not clear. Many have speculated that high avidity clones are selected for following virus infections $[38,39]$. This seems logical based on the well documented affinity maturation of antibody responses [40]. Using cell sorting, we were able to address this notion. When cells were sorted based on tetramer binding into high and low tetramer binding cells we could compare the complexity of the repertoire $\mathrm{V} \beta$ usage in the high and low tetramer binding population. These populations were highly correlated in both the 15 and 22 month samples, suggesting that the tetramer binding does not effectively discriminate these two populations. This is in accordance with our published work that shows the tetramer binding of the identical TCR is dependent on the level of CD8 expression [41].

While we have collected much less data on the response of these same mice to the NP396 epitope, we find 20 unique sequences among 93 cells sequenced with a calculated entropy of 2.58 that is only slightly more complex than the entropy calculated for the pooled gp33 mice (1.86) but enormously less for the total repertoire in a naïve mouse (6.3). Thus it seems likely that a similar contraction of the epitope specific repertoire occurs in both the gp33 and NP396 populations.

We are not the first to study the LCMV specific T cell repertoire. Lin and Welsh examined the long and short term memory response of mice to LCMV by limited sequencing and spectratyping focusing on V $\beta 13-3$ [11]. There they found a relatively stable pattern in the memory pool as long as 7 months following infection. When we examined the entropy of mice as young as 15 months post infection we saw a significant decrease in the entropy. It is possible the Welsh's group did not detect the contraction by 7 months due to focusing on TRV $\beta 13-3$. Alternatively, it might be that the the repertoire is stable for seven months and only begins to contract after that time. Our data do not allow us to rule out that possibility that the decline in repertoire complexity is not linear. This same group saw a profound narrowing of the LCMV repertoire as a result of infection with another virus [42]. While we cannot completely exclude the possibility that our mice became infected with a second virus, we find this extremely unlikely as our mice were housed in pathogen-free conditions prior to and following LCMV infection.

\section{Conclusions}

Our work demonstrates that the diversity of a memory $\mathrm{T}$ cell receptor repertoire can progressively decrease over time in the absence of persistent antigenic stimulation. This may result from a survival "program" of particular 
clonotypes determined by TCR sequence at the time of the initial immune response and clonal expansion, or may represent stochastic success of expanded clonotypes independent of their TCR.

\section{Materials and Methods \\ Mice}

C57Bl/6 J (B6) mice were purchased from Jackson labs and housed in an AALAC accredited, SPF facility at UNC. Previously infected mice were maintained under BSL2 conditions, All procedures were approved by the UNC IACUC.

\section{LCMV Infection}

Mice were infected by intraperitoneal injection of $10^{4}$ pfc of Armstrong 3 LCMV at 6 weeks of age. A single cohort of 5 mice was injected and followed over time. Mice were sacrificed and their LCMV specific repertoire was analyzed as below.

\section{Purification of LCMV specific CD8 ${ }^{+}$memory cells}

Spleen cells were prepared from mice 23 days, 15, 22 and 26 months after infection. Tetramers were assembled from $\mathrm{D}^{\mathrm{b}}$ protein produced in E. coli and stored as inclusion bodies before refolding. Proteins were refolded in vitro with either gp33 (KAVYNFATM) or NP 396 (FQPQNGQF) peptide. Purified monomers biotinylated in vitro with BirA and were purified by size exclusion chromatography and assembled with PE labeled ultraAvidin (deglycosylated avidin). LCMV gp-33 or NP-396 specific $\mathrm{CD}^{+} \mathrm{T}$ cells were purified by flow cytometry using $\mathrm{D}^{\mathrm{b}}$-gp33 or NP specific tetramers as previously described [43]. Lymphocytes were stained with anti CD8, tetramer, anti CD19 and anti CD4. CD8 ${ }^{+}$tetramer ${ }^{+} \mathrm{CD} 19^{-}$, CD4- cells were sorted using a MoFlo XDP cell sorter at the UNC flow cytometry faculty. Cells were sorted at one cell per well into 96 well plates.

\section{TCR sequencing and analysis}

Cells were sorted at one cell per well into 96 well plates directly into trizol. $4 \mu \mathrm{L}$ of an osmotic lysis buffer $(2 \mu \mathrm{L}$ PBS, $2 \mu \mathrm{L}$ nuclease-free water with $10 \mathrm{mM}$ DTT and $10 \mathrm{U}$ RNAseIN). Plates were immediately flash-frozen on dry ice and stored at $-80^{\circ} \mathrm{C}$ until $\mathrm{rt} / \mathrm{pcr}$ amplification. Sequences were determined following RT/PCR using a degenerate primer set that amplifies all TCR $\beta$ chains and cycling conditions as previously reported in Vincent et al. [41]). TCR were amplified and sequenced as previously described [41].

\section{Statistical analysis}

Statistical analysis was carried out using SOFA version 1.1.4 (Paton-Simpson \& Associates Ltd, Auckland, New Zealand). P values for Pearson's correlations were corrected for multiple comparison using Bonferroni correction. Shannon Entropy was calculated using software developed and supplied by T. Kepler (Boston University) as we previously described [44].

\section{Nomenclature}

We have consistently used the current IMGT nomenclature in this manuscript [45].

\section{Additional file}

Additional file 1: Table 1. Summary of Sequence Data.

\section{Abbreviations}

TCE: T cell expansion; LCMV: Lymphocytic choriomeningitis virus.

\section{Competing interests}

The authors declare no competing interests.

\section{Authors contributions}

$A B, B V$ and $S S$ carried out the cell purification and the DNA sequencing. $A B$, $B V$ and $H K$ carried out the bioinformatics analyses. JAF conceived of the project and drafted the manuscript. All authors revised the manuscript and analyses and approved of the manuscript.

\section{Acknowledgments}

Tom Kepler, Boston University supplied computer programs used in the analysis and helped with their implementation. We thank Drs. Megan Smithies, Michael Kuhns and Kurt Griffin for critically reading the manuscript. Sequencing was supported by a grant from the University of North Carolina Lineberger Cancer Center, University Cancer Research Fund and NIH Contract HHSN 272201100017C (NIH/NIAID N01-AI-00017).

\section{Author details}

${ }^{1}$ Department of Immunobiology, University of Arizona, Tucson, AZ 85724, USA. ${ }^{2}$ Departments of Medicine, University of North Carolina, Chapel Hill, NC 27599, USA. ${ }^{3}$ Microbiology and Immunology, University of North Carolina, Chapel Hill, NC 27599, USA.

Received: 29 June 2012 Accepted: 22 July 2012

Published: 15 August 2012

\section{References}

1. Khanolkar A, Fuller MJ, Zajac AJ: CD4 T cell-dependent CD8 T cell maturation. J Immunol 2004, 172:2834-2844.

2. Graw F, Richter K, Oxenius A, Regoes RR: Comparison of cytotoxic T lymphocyte efficacy in acute and persistent lymphocytic choriomeningitis virus infection. Proc Biol Sci 2011, 278:3395-3402.

3. Matloubian M, Concepcion RJ, Ahmed R: $\mathrm{CD}^{+} \mathrm{T}$ cells are required to sustain $\mathrm{CD}^{+}$cytotoxic T-cell responses during chronic viral infection. J Virol 1994, 68:8056-8063.

4. von Herrath MG, Yokoyama M, Dockter J, Oldstone MB, Whitton JL: CD4deficient mice have reduced levels of memory cytotoxic T lymphocytes after immunization and show diminished resistance to subsequent virus challenge. J Virol 1996, 70:1072-1079.

5. Murali-Krishna K, Lau LL, Sambhara S, Lemonnier F, Altman J, Ahmed R: Persistence of memory CD8 T cells in MHC class I-deficient mice. Science 1999, 286:1377-1381.

6. Tanchot C, Lemonnier FA, Perarnau B, Freitas AA, Rocha B: Differential requirements for survival and proliferation of CD8 naive or memory $T$ cells. Science 1997, 276:2057-2062.

7. Jamieson BD, Ahmed R: T cell memory. Long-term persistence of virusspecific cytotoxic T cells. J Exp Med 1989, 169:1993-2005.

8. Frelinger JA, Garba ML: Responses to smallpox vaccine. N Engl J Med 2002, 347:689-690. 
9. Van Epps HL, Terajima M, Mustonen J, Arstila TP, Corey EA, Vaheri A, Ennis FA: Long-lived memory $T$ lymphocyte responses after hantavirus infection. J Exp Med 2002, 196:579-588.

10. Hikono H, Kohlmeier JE, Ely KH, Scott I, Roberts AD, Blackman MA, Woodland DL: T-cell memory and recall responses to respiratory virus infections. Immunol Rev 2006, 211:119-132.

11. Lin MY, Welsh RM: Stability and diversity of T cell receptor repertoire usage during lymphocytic choriomeningitis virus infection of mice. J Exp Med 1998, 188:1993-2005.

12. Lin MY, Selin LK, Welsh RM: Evolution of the CD8 T-cell repertoire during infections. Microbes Infect 2000, 2:1025-1039.

13. Blattman JN, Sourdive DJ, Murali-Krishna K, Ahmed R, Altman JD: Evolution of the $T$ cell repertoire during primary, memory, and recall responses to viral infection. J Immunol 2000, 165:6081-6090.

14. Pewe LL, Netland JM, Heard SB, Perlman S: Very diverse CD8 T cell clonotypic responses after virus infections. J Immunol 2004, 172:3151-3156.

15. Posnett DN, Yarilin D, Valiando JR, Li F, Liew FY, Weksler ME, Szabo P: Oligoclonal expansions of antigen-specific $C D 8^{+} \mathrm{T}$ cells in aged mice. Ann N Y Acad Sci 2003, 987:274-279.

16. Kohlmeier JE, Connor LM, Roberts AD, Cookenham T, Martin K, Woodland $\mathrm{DL}$ : Nonmalignant clonal expansions of memory $\mathrm{CD} 8^{+} \mathrm{T}$ cells that arise with age vary in their capacity to mount recall responses to infection. $\mathrm{J}$ Immunol 2010, 185:3456-3462.

17. Messaoudi I, Warner J, Nikolich-Zugich J: Age-related $\mathrm{CD}^{+} \mathrm{T}$ cell clonal expansions express elevated levels of CD122 and CD127 and display defects in perceiving homeostatic signals. J Immunol 2006, 177:2784-2792.

18. Ahmed M, Lanzer KG, Yager EJ, Adams PS, Johnson LL, Blackman MA: Clonal expansions and loss of receptor diversity in the naive CD8 T cell repertoire of aged mice. J Immunol 2009, 182:784-792.

19. Messaoudi I, LeMaoult J, Guevara-Patino JA, Metzner BM, Nikolich-Žugich J: Age-related CD8 T Cell Clonal Expansions Constrict CD8 T Cell Repertoire and Have the Potential to Impair Immune Defense. The J Exp Med 2004, 200:1347-1358.

20. LeMaoult J, Messaoudi I, Manavalan JS, Potvin H, Nikolich-Zugich D, Dyall R, Szabo P, Weksler ME, Nikolich-Zugich J: Age-related dysregulation in CD8 T cell homeostasis: kinetics of a diversity loss. J Immunol 2000, 165:2367-2373.

21. Yager EJ, Ahmed M, Lanzer K, Randall TD, Woodland DL, Blackman MA Age-associated decline in T cell repertoire diversity leads to holes in the repertoire and impaired immunity to influenza virus. The J Exp Med 2008, 205:711-723.

22. Ku CC, Kappler J, Marrack P: The growth of the very large $C D 8^{+} \mathrm{T}$ cell clones in older mice is controlled by cytokines. J Immuno/ 2001, 166:2186-2193.

23. Callahan JE, Kappler JW, Marrack P: Unexpected expansions of CD8bearing cells in old mice. J Immunol 1993, 151:6657-6669.

24. Ely KH, Ahmed M, Kohlmeier JE, Roberts AD, Wittmer ST, Blackman MA, Woodland DL: Antigen-specific CD8 ${ }^{+} \mathrm{T}$ cell clonal expansions develop from memory $T$ cell pools established by acute respiratory virus infections. J Immunol 2007, 179:3535-3542.

25. Nikolich-Zugich J, Slifka MK, Messaoudi I: The many important facets of T-cell repertoire diversity. Nat Rev Immunol 2004, 4:123-132.

26. Jost L: Partitioning diversity into independent alpha and beta components. Ecology 2007, 88:2427-2439.

27. Chao A, Shen T-J: Nonparametric estimation of Shannon's index of diversity when there are unseen species in sample. Environ Ecol Stat 2003, 10:429-443.

28. Kaech SM, Wherry EJ, Ahmed R: Effector and memory T-cell differentiation: implications for vaccine development. Nat Rev Immunol 2002, 2:251-262

29. Nikolich-Zugich J, Li G, Uhrlaub JL, Renkema KR, Smithey MJ: Age-related changes in CD8 T cell homeostasis and immunity to infection. Semin Immunol 2012,

30. Murasko DM, Jiang J: Response of aged mice to primary virus infections. Immunol Rev 2005, 205:285-296.

31. Deng $Y$, Jing $Y$, Campbell $A E$, Gravenstein $S$ : Age-related impaired type $1 \mathrm{~T}$ cell responses to influenza: reduced activation ex vivo, decreased expansion in CTL culture in vitro, and blunted response to influenza vaccination in vivo in the elderly. J Immunol 2004, 172:3437-3446.

32. Mongkolsapaya J, Dejnirattisai W, Xu XN, Vasanawathana S, Tangthawornchaikul N, Chairunsri A, Sawasdivorn S, Duangchinda T, Dong
T, Rowland-Jones $S$, et al: Original antigenic sin and apoptosis in the pathogenesis of dengue hemorrhagic fever. Nat Med 2003, 9:921-927.

33. Degauque N, Boeffard F, Foucher Y, Ballet C, Brouard S, Soulillou JP: The blood of healthy individuals exhibits CD8 T cells with a highly altered TCR V $\beta$ repertoire but with an unmodified phenotype. PLOS One 2011, 6:e21240.

34. Messaoudi I, Warner J, Nikolich-Zugich D, Fischer M, Nikolich-Zugich J: Molecular, cellular, and antigen requirements for development of ageassociated T cell clonal expansions in vivo. J Immunol 2006, 176:301-308,

35. Pircher $H$, Moskophidis D, Rohrer U, Burki $K$, Hengartner $H$, Zinkernagel RM: Viral escape by selection of cytotoxic T cell-resistant virus variants in vivo. Nature 1990, 346:629-633.

36. Puglielli MT, Zajac AJ, van der Most RG, Dzuris JL, Sette A, Altman JD, Ahmed R: In Vivo Selection of a Lymphocytic Choriomeningitis Virus Variant That Affects Recognition of the GP33-43 Epitope by $\mathrm{H}-2 \mathrm{D}^{\mathrm{b}}$ but Not H-2K ${ }^{\mathrm{b}}$. J Virol 2001, 75:5099-5107.

37. Busch DH, Pamer EG: T cell affinity maturation by selective expansion during infection. J Exp Med 1999, 189:701-710.

38. Williams MA, Ravkov EV, Bevan MJ: Rapid culling of the $\mathrm{CD}^{+} \mathrm{T}$ cell repertoire in the transition from effector to memory. Immunity 2008 , 28:533-545.

39. Savage PA, Boniface JJ, Davis MM: A kinetic basis for T cell receptor repertoire selection during an immune response. Immunity 1999, 10:485-492.

40. Bachmann MF: The role of germinal centers for antiviral B cell responses. Immunol Res 1998, 17:329-344.

41. Maile R, Siler CA, Kerry SE, Midkiff KE, Collins EJ, Frelinger JA: Peripheral "CD8 tuning" dynamically modulates the size and responsiveness of an antigen-specific T cell pool in vivo. J Immunol 2005, 174:619-627.

42. Cornberg M, Chen AT, Wilkinson LA, Brehm MA, Kim S-K, Calcagno C, Ghersi D, Puzone R, Celada F, Welsh RM, Selin LK: Narrowed TCR repertoire and viral escape as a consequence of heterologous immunity. J Clin Invest 2006, 116:1443-1456.

43. Wang B, Maile R, Greenwood R, Collins EJ, Frelinger JA: Naive CD8 ${ }^{+}$T cells do not require costimulation for proliferation and differentiation into cytotoxic effector cells. J Immunol 2000, 164:1216-1222.

44. Vincent BG, Young EF, Buntzman AS, Stevens R, Kepler TB, Tisch RM, Frelinger JA, Hess PR: Toxin-coupled MHC class I tetramers can specifically ablate autoreactive $\mathrm{CD}^{+} \mathrm{T}$ cells and delay diabetes in nonobese diabetic mice. J Immunol 2010, 184:4196-4204.

45. Lefranc MP: WHO-IUIS Nomenclature Subcommittee for immunoglobulins and T cell receptors report. Immunogenetics 2007, 59:899-902.

doi:10.1186/1742-4933-9-17

Cite this article as: Bunztman et al:: The LCMV gp33-specific memory T cell repertoire narrows with age. Immunity \& Ageing 2012 9:17.

\section{Submit your next manuscript to BioMed Central and take full advantage of:}

- Convenient online submission

- Thorough peer review

- No space constraints or color figure charges

- Immediate publication on acceptance

- Inclusion in PubMed, CAS, Scopus and Google Scholar

- Research which is freely available for redistribution 